\title{
Gallbladder Cancer: A Hospital Based Study
}

\author{
Sharma $A^{1}$, Thapa $P^{2}$, Dhakal $A^{3}$
}

\begin{abstract}
Introduction: Gallbladder carcinoma $(\mathrm{GBC})$ is the commonest cancer of the biliary tree and the most frequent cause of death from biliary malignancies. The overall resection rates at presentation range from $10 \%-30 \%$ only. Therefore, a large number of patients are inoperable with overall survival of only 6-8 months. Palliation of the pain, jaundice, pruritus is a big challenge in patients with advanced disease. Methods: A prospective cross sectional study of patients with GBC during the period of October 2014 to September 2017 at Nepalgunj Medical College and Teaching Hospital, Kohalpur, department of surgery. Results: There were 216 cases of gastrointestinal malignancies with 54(25\%) GBC. There was female (75.92\%) preponderance with a male to female ratio of $1: 3.15$. The mean age was $61.41 \pm 12.18$. The most common symptom at presentation was pain in a right upper abdomen (87.03\%) followed by abdominal lump (41.23\%) and surgical jaundice (18.51\%). Fundus (70.37\%) was the most common site of involvement followed by body (5.55\%) and neck (24.05\%). Gall stone was associated in 44 (81.48\%) patients. Only 7 (12.96\%) patients had localized GBC, 25 (46.29\%) patients had locally advanced disease and 22 (40.74\%) had metastatic disease. Liver was the commonest site of metastatis followed by peritoneum and two patients had left supraclavicular lymph node metastatis. There were two (3.72\%) incidental gall bladder cancer after laparoscopic cholecystectomy. 13 (24.07\%) patients were operated with intention of radical cholecystectomy but only six (46.15\%) patient could undergo radical resection. Staging laparoscopy was done in all patients except for incidental gall bladder cancer. Metastatic disease was identified in 3 (23.07\%) on staging laparoscopy. In eight (61.33\%) among 13 patients the disease was unresectable. The most common histology was adenocarcinoma and most common stage was stage III and stage IV when both operated and non-operated groups were combined. Conclusions: GBC was the commonest gastrointestinal tract cancer with a female preponderance. A majority of patients were inoperable at presentation with pain in abdomen being the most common symptom. Surgery although is the main stay of treatment is not possible in many.
\end{abstract}

Key words: Adenocarcinoma, clinical presentation, gallbladder cancer, staging laparoscopy

\section{INTRODUCTION}

Gastrointestinal malignancies are a leading cause of both mortality and morbidity ${ }^{1}$. Gallbladder malignancy is the fifth most common malignancy of the gastrointestinal tract and the most common cause of death from biliary malignancies ${ }^{2}$. Although it is unusual in western countries where the incidence rates range between 0.4 and 0.8 in men and between 0.6 and 1.4 in women in 100,000 population ${ }^{3}$. The incidence of gallbladder cancer is significantly higher in northern part of India, east Asia, eastern Europe and south America ${ }^{4}$. The incidence of gall bladder cancer specially in northern part ranges from 1 per 100000 for males to 10 per 100,000 in females ${ }^{5}$.

The etiology of gallbladder cancer is unknown, however it is found associated with gall stone disease in $75-90 \%$ patients.

\footnotetext{
1. Dr. Anup Sharma

2. Dr. P. Thapa

3. Dr. A. Dhakal
}

Address for correspondence:

Dr. Anup Sharma

Department of Surgery

Nepalgunj Medical College \& Teaching Hospital

Kohalpur, Banke, Nepal

Email: anup_sharma88@yahoo.com
Only $25 \%$ patients have gall bladder cancer localized to gall bladder. Most of the patients have advanced disease with a median overall survival of only about 6 months after the diagnosis and the 5 year survival of around $5 \%$. The objectives of the study were to evaluate the prevalence, association with gall stone, clinical profile and histological pattern of gall bladder cancer.

\section{MATERIALS AND METHODS}

This was a prospective cross sectional study which was carried out in the department of surgery, Nepalgunj Medical College and Teaching Hospital, Kohalpur from the period of 2014 October to 2017 September. All patients with gall bladder cancer were included. After taking history and clinical examination, clinical and biochemical blood investigations were done. Ultrasound (USG) abdomen and pelvis and CECT abdomen and pelvis were done for the clinical staging. Preoperative USG guided cytological examination or biopsy was done as indicated. Type of surgery, operative findings and final histology were noted in those who underwent surgery.

\section{RESULTS}

There were 216 patients of gastrointestinal malignancy. The diagnosis of GI malignancy was confirmed by histology, who underwent Surgery and those who did not undergo Surgery. Diagnosis was confirmed either on radiological or cytological 
examination. Among them the most common was gall bladder cancer comprising 54(25\%) cases. second most common was gastric malignancies comprising $41(18.9 \%)$ cases followed by colorectal cancers, periampullary and proximal cholangio carcinomas. (Figure 1).

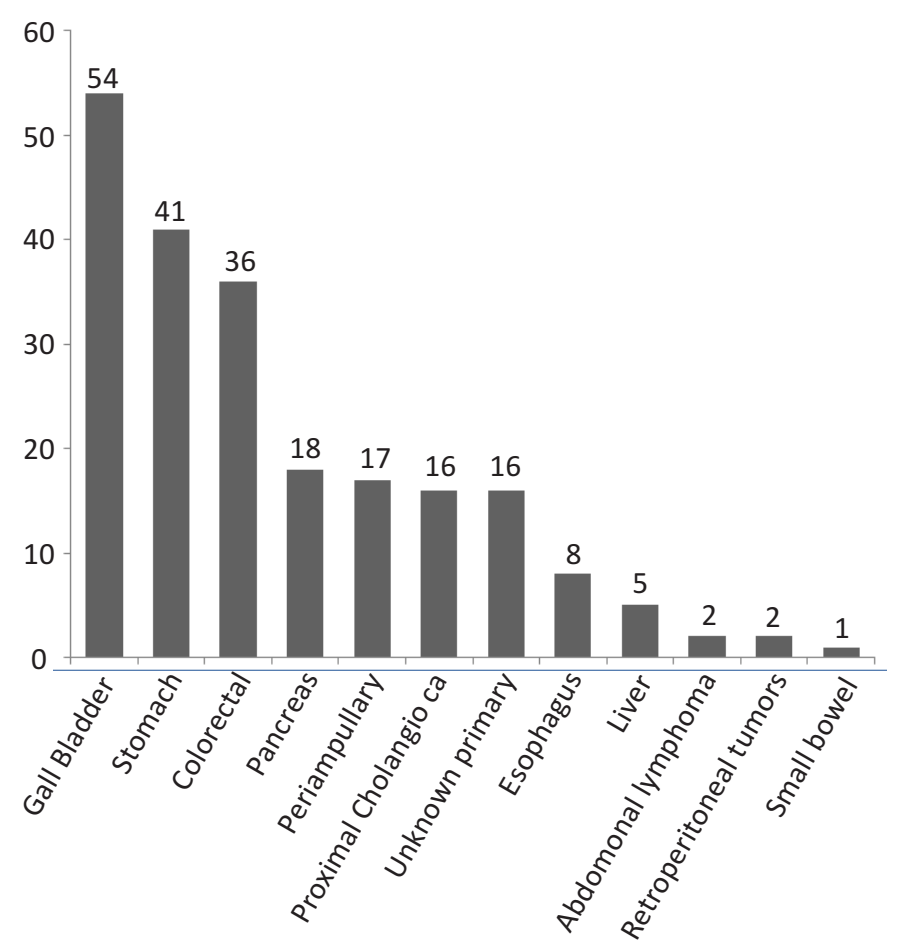

Figure 1: Frequency of gastrointestinal cancers $(n=216)$

There were $41(75.92 \%)$ females and $13(24.07 \%)$ males, the ratio being 3.15:1. The age ranged from 30-92 with a mean age of $61.41 \pm 12.18$ years. Maximum number of patients was in the age group of 50-70. Mean duration of illness was 2.4 months (15 months) with pain in right hypochondrium (87.03\%) being the most common presentation. $41.23 \%$ had lump in right hypochondrium, $18.51 \%$ had surgical jaundice and $46.67 \%$ had losses of weight and $67.02 \%$ had loss of appetite (Table II).

\begin{tabular}{|l|c|}
\hline Clinical profile & $\mathbf{n ( \% )}$ \\
\hline Age range & $30-92$ \\
\hline Mean age & $61.4 \pm 12.18$ \\
\hline Male & $13(24.07 \%)$ \\
\hline Female & $41(75.92 \%)$ \\
\hline Right hypchondrium pain & $87.03 \%$ \\
\hline Right hypochondrium lump & $41.23 \%$ \\
\hline Surgical jaundice & $18.51 \%$ \\
\hline Loss of appetite & $67.02 \%$ \\
\hline Loss of weight & $46.67 \%$ \\
\hline
\end{tabular}

Table II: Clinical profile of patients
All 54 patients underwent USG abdomen however 43 patients only underwent CECT abdomen. The most common radiologic finding was focal/diffuse asymmetrical gallbladder wall thickening. Fundus $(70.37 \%)$ was the most common site of involvement followed by body (5.55\%) and neck (24.08\%). Gall stone was associated in 44 (81.48\%) patients.

Only $7(12.96 \%)$ patients had their disease localized to the gallbladder, 25(46.29\%) patients had locally advanced disease (i.e. either invasion of the liver or other adjacent structures like duodenum, stomach, colon or both liver and adjacent structure or paraaortic, interaortocaval and celiac lymphnode enlargement), 22 (40.74\%) had metastatic disease. Liver was the commonest site of metastatsis followed by peritoneum and two patients had left supraclavicular lymphnode metastatis.

Two (3.72\%) had incidental gall bladder cancer after laparoscopic cholecystectomy. Both were adinocarcinoma, one was T2 and another was T1a on histology. The patient with T2 lesion underwent completion radical cholecystectomy and on final histopathology there was no residual disease. No further treatment was offered to T1a disease.

13(24.07\%) patients were operated with intention of radical cholecystectomy but only six (46.15\%) patient could undergo radical cholecystectomy. The final histology of one patient among them was xanthomatous cholecystitis hence excluded. Staging laparoscopy was done in all patients except for

\begin{tabular}{|l|c|c|}
\hline $\begin{array}{l}\text { Histopathologic } \\
\text { Features }\end{array}$ & $\begin{array}{c}\text { Operated } \\
\text { (n=13) }\end{array}$ & $\begin{array}{c}\text { Nonopereted } \\
\text { (n=41) }\end{array}$ \\
\hline Adenocarcinoma & $11(84.61 \%)$ & $33(80.48 \%)$ \\
\hline $\begin{array}{l}\text { Squamous cell } \\
\text { carcinoma }\end{array}$ & $1(7.69 \%)$ & \\
\hline xanthogranulomatous & $1(7.69 \%)$ & \\
\hline Well defferentiated & $2(15.38 \%)$ & \\
\hline Moderately differentiated & $6(46.15 \%)$ & \\
\hline Poorly differentiated & $4(30.76 \%)$ & \\
\hline T1a & $1(7.69 \%)$ & \\
\hline T2 & $3(60 \%)$ & $7(17.07 \%)$ \\
\hline T3 & $2(40 \%)$ & $34(82.96 \%)$ \\
\hline T4 & $4(80 \%)$ & $21(51.21 \%)$ \\
\hline N0 & $3(60 \%)$ & $11(26.82 \%)$ \\
\hline N1 & $2(40 \%)$ & $27(65.82 \%)$ \\
\hline N2 & $1(20 \%)$ & $17(41.46 \%)$ \\
\hline M1 & $3(23.07 \%)$ & $19(46.34 \%)$ \\
\hline LVI positive & $2(40 \%)$ & \\
\hline PNI positive & $1(20 \%)$ & \\
\hline LVI and PNI positive & $2(40 \%)$ & \\
\hline & & \\
\hline
\end{tabular}

Table III: Histopathological characteristics; LVI: lymphovascular invasion, PNI: perineural invasion 
incidental gall bladder cancer. All five patients had RO resection, their histopathologic characteristics are shown in table III. In nonoperated patients clinical staging was done by CT abdomen. In eight among 13 patients the disease was unresectable. Two patients had peritoneal and one had $(3 / 23 \%)$ discontinuous liver metastatsis on staging laparoscopy and were spared from laparotomy. Their histopathology reports were metastatic adenocarcinoma. In remaining five patients radical resection was not possible because of locally advanced disease or N2 nodal disease (vascular invasion, nonregional lymphnodal involvement e.g celiac, paraaortic and interaortoval). Biopsies were adenocarcinoma in all. USG guided FNAC was done in 33 nonoperated patients out of 41 , all were adenocarcinoma.

\section{DISCUSSION}

Fifty four patients with gall bladder cancer (GBC) were evaluated. The incidence of GBC has geographic and ethnic variations. It is more common in east Asia, south America, India and Pakistan ${ }^{5,7}$. In our study also the most common among all gastrointestinal malignancies was GBC. Nepalgunj Medical College, Nepalgunj is a western part of Nepal, where this study was conducted which shares a boarder with the northern part of India where GBC is very common; this might be one of the explanations for the higher incidence of $\mathrm{GBC}$ in this region.

GBC increases with age. The mean age in this study was 61.41. Other studies have also reported the similar age group of incidence ${ }^{8,9}$. GBC is more common in females. In this study the male to female ratio was $1: 3.15$ with $75.22 \%$ being female patients. Previous studies have also reported the similar data ${ }^{10}$. Clinical presentation of $\mathrm{GBC}$ varies from being asymptomatic to pain, lump in the abdomen and surgical jaundice. In this study right hypochondrial pain and lump were the most common clinical features. This is in concordance with other studies ${ }^{11}$. The etiology of GBC is unknown but it is commonly found to be associated with Gall bladder stone. We found this association as high as $81.48 \%$, which is quite similar to the data in literature ${ }^{12}$.

One of the reasons behind the dismal survival of GBC is late presentation. At the time of presentation many are either locally advanced or metastatic ${ }^{13}$. In the present study $46.29 \%$ had locally advanced and $40.74 \%$ had metastatic disease. Only 13 patients among 54 underwent surgery and out of those 13 only six patients underwent $\mathrm{R} 0$ radical resection. The low rate of surgery was due to the advance nature of the disease at presentation. The other reasons are economic constraints and dismal survival. Adenocarcinoma was the most common histology except for one squamaous cell carcinoma. GBC metastasizes more commonly to the liver, lymph nodes and peritoneum ${ }^{14}$. In this study also the liver; Iymph nodes were the most common sites of metastasis in both operated and nonoperated patients. Among the patients who were operated 3 had metastasis which was detected on staging laparoscopy. In these patients laparotomy was not done. As a preoperative staging, laparoscopy can detect up to $20-25 \%$ of metastatic disease, sparing the patients from the morbidity of laparotomy ${ }^{15,16}$.

\section{CONCLUSIONS}

$\mathrm{GBC}$ was the commonest gastrointestinal malignancy with high incidence at $5^{\text {th }}$ and $6^{\text {th }}$ decade of life. It is much more common in females than in males. Association with cholelithiasis is very high. A majority of patients were inoperable at the time of presentation with pain abdomen being the most common symptom. Adenocarcinoma is the commonest histologic type of GBC. Preoperative staging laparoscopy in locally advanced $\mathrm{GBC}$ can spare the patients from laparotomy and thereby reducing the morbidity.

\section{REFERENCES}

1. Purohit DMB, Purohit DTM, Gandhi DSH, Dobaria DRD. Histopathological diagnosis Of Gastro intestinal malignancies- A retrospective study. NJIRM 2013; 4:107-12.

2. Schauer RJ, Meyer G, Baretton G, Schildberg FW, Rau HG. Prognostic factors and long-term results after surgery for gallbladder carcinoma: a retrospective study of 127 patients. Langenbeck's Arch Surg 2001; 386:110-7.

3. Kapoor VK, McMichael AJ. Gallbladder cancer: an 'Indian' disease. Natl Med J India. 2003; 16:209-13.

4. National Cancer Registry Programme. Two-year Report of the Population Based Cancer Registries 1997-1998. New Delhi: Indian Council of Medical Research; 2002.

5. Indian council of Medical Research (ICMR):Annual report of population based cancer registries of the national cancer registry programme, New Delhi ICMR publication 1996, pp18.

6. Serra I, Calvo A, Baez S, etal. Risk factors for gall bladder cancer. An international collaborative case control study. Cancer 1996;78:1515-7.

7. Carcinoma gallbladder: Demographic and clinicopathological profile in Indian patients. Onc J India 2018; 2: 3-6.

8. Hundal R, Shaffer EA. Gallbladder cancer: Epidemiology and outcome. Clin Epidemiol 2014; 6:99-109.

9. Fuks D, Regimbeau JM, Le Treut YP, Bachellier P, Raventos A, Pruvot FR, et al. Incidental gallbladder cancer by the AFC-GBC2009 study group. World J Surg 2011;35:1887-9

10. Randi G, Franceschi S, La Vecchia C. Gallbladder cancer worldwide: Geoghraphic distribution and risk factors. Int J cancer 2006; 118:1591-1602.

11. Khan RA, Wahab S et al. Advanced presentation of Gallbladder cancer: Epidemio clinicopathological study to evaluate the risk factors and assess the outcome. .J Pak Med Assoc 2010; 60:217-9.

12. Kalita D, Pant Let al. Impact of Routine Histopathological Examination of Gall Bladder Specimens on Early Detection of Malignancy - A Study of 4,115 Cholecystectomy Specimens. Asian Pac J Cancer Prev 2013;14:3315-8

13. Batra Y, Pal S, Dutta U, Desai P, Garg PK, Makharia G, et al. Gallbladder cancer in India: A dismal picture. J Gastroenterol Hepatol 2005; 20:309-14.

14. Dwivedi AN, Jain S, Dixit R. Gall bladder carcinoma: Aggressive malignancy with protean loco-regional and distant spread. World J Clin Cases 2015;3: 231-44.

15. Weber SM, DeMatteo RP, Fong Y, Blumgart LH, Jarnagin WR: 
Staging laparoscopy in patients with extra hepatic biliary carcinoma. Ann Surg 2002; 235: 392-99.

16. Kriplani AK, Jayant S, Kapur BML: Laparoscopy in primary carcinoma of the gallbladder. Gastrointest Endosc 1992; 38: 326-

29. 